\title{
Using Decision Scenarios to Evaluate Laypeople's Computer-Mediated Medication Information Sharing Choices
}

\author{
Jenna L. Marquard \\ College of Engineering \\ University of Massachusetts, Amherst \\ marquard@engin.umass.edu
}

\author{
Patricia Flatley Brennan \\ College of Engineering \\ University of Wisconsin - Madison \\ pbrennan@ie.engr.wisc.edu
}

\begin{abstract}
Motivation - Abstract surveys are currently the primary source of data guiding policy-makers as they frame laypeople's choices to electronically share their health information with care providers. Research approach - We presented laypeople $(\mathrm{N}=31)$ with two decision scenarios; one required them to choose whether to share their medication information with three types of physicians, the other required them to recommend sharing choices to four different patients. Findings/Design - Participants' sharing choices, their rationale for their choices, and their recommendations for other patients were contrary to what might be expected, given abstract survey responses. Research limitations/Implications - Our focus on sharing medication information with physicians and recruitment of only neurology patients limits the generalizability of the findings. Originality/Value -Walking decision-makers through realistic decision scenarios, and asking them to provide recommendations to other patients allowed us to assess laypeople's true decision criteria. This research therefore demonstrates the value of using realistic decision scenarios to inform policymaking.
\end{abstract}

Keywords

Health care, informatics, policy, decision-making, decision scenario

\section{INTRODUCTION}

Within our system of health care, there has been an increased focus on consumers - "laypeople" - as decision-makers. Laypeople no longer receive care solely at formal institutions, but also conduct self-care health work within and around their homes. Laypeople, instead of solely relying on their care providers for advice and care, have become partners with these care providers in determining, planning and managing the course of their own care (Kaplan, 2001). While the heightened engagement among laypeople with their health care has significant benefits, these laypeople are now faced with a complex set of choices in a domain unfamiliar to them. These choices range from which treatment alternatives to choose from to whether they should participate in a given research study (Holmes-Rovner \& Wills, 2002; Say \& Thomson, 2003). More recently, changes in health information technologies, specifically personal health records (PHRs), are posing new challenges to patients who now must give broad permissions to share their health information.

\section{The Decision Context: Personal Health Records (PHRs)}

Policy groups and those designing technical platforms for personal health records (PHRs) - lifelong copies of people's health information that are owned and controlled by individuals - view PHRs as a way for laypeople to more readily engage in their own health care. A PHR might contain copies of records produced by care providers but also annotations to those records and records produced by the layperson. Layperson-produced records could detail health maintenance activities occurring in the home, including diet and exercise logs, blood sugar measurements or medication administration logs. In their "Joint Position Statement for Consumers of Health Care," the American Health Information Management Association (AHIMA) and the American Medical Informatics Association (AMIA) propose that "using a PHR will help people make better health decisions and improves quality of care by allowing them to access and use information needed to communicate effectively with others about their health care" (The Value, 2007). Although they hold promising value, PHRs will require laypeople to set policies regarding whether to share their health information.

National policy organizations and field leaders suggest that laypeople may grant access rights to their PHR at the level of individual data elements and care providers. In June 2007, the Office of the National Coordinator for Health Information Technology (ONC) released a detailed consumer-centered use case - revised based on 307 pieces of feedback from 41 organizations (Consumer Empowerment, 2007). The use case, aimed at reflecting the policy perspectives of those concerned with protecting consumer rights, includes recommended PHR needs. Included in this list of needs are: 
Privacy and access control: Ability for a consumer to identify those providers which are permitted to access information in the consumers' PHR, and which of those data they are permitted to access. Ability to communicate the consumer's decisions to other entities which also hold data about the consumer (Consumer Empowerment, 2007).

The American Health Information Management Association (AHIMA) and American Medical Informatics Association (AMIA) also state one of the basic principles of a PHR to be that "Every person should have control over how their PHR information is accessed, used and disclosed" (The Value, 2007).

As might be expected, some groups have designed technical PHR solutions that both mirror and drive these policy statements. The Children's Hospital Informatics Program (CHIP) in Boston, MA has developed one personally controlled health record (PCHR) system, Indivo ${ }^{\circ}$. Beyond making personal control explicit in the title of their approach, the developers of Indivo ${ }^{\circledR}$ see their system as "essentially an inversion of the current approach to medical records, in that the record resides with the patients and the patients grant permissions to institutions, clinicians, researchers, and other users of medical information" (The Children's Hospital Informatics Program, 2007).

\section{The Changing Context and Nature of Laypeople's Choices}

Both policy groups and those designing technical platforms for PHRs describe a unified patient medication-list as an early application of PHRs (Tang, Ash, Bates, Overhage, \& Sands, 2006; Yasnoff et al., 2004). Many in the health policy, technology and delivery communities hope unified or reconciled medication-lists will temper the prevalence of medication errors by providing care providers with a complete and accurate list of their patients' medications (Aspden, Wolcott, Bootman, \& Cronenwett, 2006; Opportunities, 2005). Given that reconciled medications lists are a likely application of PHRs, consider Kristine's story, described below, as an example of one layperson's set of choices addressing whether to share her medication information through a PHR:

Kristine is a 36 year-old single mother with two young children who suffers from a seizure disorder. After trying several medications without success, she now uses UCB Pharma's KEPPRA ${ }^{\circledR}$ to control her seizure disorder. When Kristine started using KEPPRA ${ }^{\circledR}$, she began having mood swings as a side effect of the medication. Because KEPPRA ${ }^{\circledR}$ works so well to control her seizure disorder, Kristine has chosen to take Forest Pharmaceuticals' LEXAPRO ${ }^{\circledR}$ as a mood stabilizer to temper this side effect. Recently, Kristine began taking Pfizer's LIPITOR ${ }^{\circ}$ to lower her high cholesterol. Kristine also takes a multivitamin daily because of potential vitamin depletion from the use of KEPPRA®.

Kristine has recently been told about an electronic tool, called a personal health record, which she could use to manage the information about her medications. She could also use this tool to allow each of her care providers to electronically access information about each of her medications, even if they did not prescribe the medication. Kristine thinks this tool could save her time by allowing her to decide ahead of time who could automatically view information about her medications.

Underlying these choices to share her medication information with different care providers are complex issues that Kristine must weigh. For instance, both seizure disorder medications and mood stabilizers may carry social labels, causing her providers to treat her differently. Kristine may not want her care providers to infer information about her seizure disorder or mental health from her medication information. Shared medication information may not clearly describe that the mood stabilizer is being taken in response to a side effect of KEPPRA ${ }^{\circledR}$, which could be important for Kristine to clarify with her care providers. While these information-disclosure issues may be present, clinical care issues may also be present. LIPITOR ${ }^{\circ}$, Kristine's cholesterol-lowering medication, has potential risks when used in people who have uncontrolled seizures. Although Kristine's seizure disorder appears to be under control, she may have health risks if the care provider prescribing LIPITOR ${ }^{\circledR}$ is unaware of her seizure disorder. If the care provider is aware of her seizure disorder and the effectiveness of the medication she is taking to control her seizures, the provider can alter her cholesterol medication as needed.

Although a potentially valuable tool is available to Kristine, using an electronic personal health record would require her to make a complex set of choices about sharing her medication information. While Kristine currently makes these choices each time she visits a care provider, this tool would require her to set policies that would remain in effect until she explicitly changes them. These choices presume Kristine will weigh potential clinical benefits and information-disclosure concerns related to sharing her medication information with her care providers. As Kristine makes these choices, she is likely to have incomplete information about the nature and likelihood of these benefits and concerns, and the nature and likelihood of potential outcomes related to sharing her medication information.

Although laypeople currently make choices about sharing their medication information, they do so many times - at each encounter with their health care providers. Sharing medication information through a PHR will require lay decisionmakers to make choices with some permanence. Instead of making sharing choices at specific points in time, laypeople will be asked to make sharing choices in advance of any treatment they receive, so they will essentially be constructing 
sharing policies without knowing what care they will require in the future. Additionally, these lay decision-makers, while likely having some experience within the health care system, are not experts in the domain of the decision.

There are real yet uncertain outcomes associated with sharing medication information through a PHR. Laypeople may realize clinical care benefits from sharing. For instance, a physician prescribing a new medication to a patient may be able to prevent an interaction based on information about the patient's current medications. One hospital reduced potential adverse drug events by $80 \%$ when pharmacy technicians obtained patient medication histories prior to their scheduled surgery (Michels \& Meisel, 2003). The Joint Commission also maintains a database of medication errors resulting in death or major injury. Of the 350 events in the database, approximately 31 percent are thought to be avoidable through reconciled medication-lists.

Care providers may be able to monitor the side effects of medications more closely if they know which medications a patient is taking. Two rheumatological drugs, Chloroquine and hydroxychloroquine, require patients to have both their primary care physician and an optometrist monitor their vision (Hadjikoutis, Morgan, Wild, \& Smith, 2005). In Kristine's case, she may have benefited from care providers more closely monitoring the psychological side effects of KEPPRA ${ }^{\circledR}$ or use of LIPITOR ${ }^{\circledR}$ as a patient with a history of seizures. These benefits are not guaranteed, however, as providers need ways to appropriately integrate this new information into their practice.

Laypeople may also see information-disclosure concerns realized from sharing their medication information. Patients' medication information may serve as a proxy for their diagnosis and they may be treated in a discriminating way by their care provider because of that diagnosis, so may have different care outcomes (Rintamaki, Davis, Skripkauskas, Bennett, \& Wolf, 2006; Sengupta et al., 2006; Sher, McGinn, Sirey, \& Meyers, 2005). Some medications may disclose the mental health, HIV, sexually transmitted disease, or transgender or transsexual status of an individual. Additionally, a care provider might make an incorrect inference about a patient's diagnoses based on information about each of his/her medications. In Kristine's case, she may be concerned that providers would infer an incorrect mental health diagnosis based on the knowledge that she is taking LEXAPRO ${ }^{\circ}$. Laypeople may also be concerned about their medication information being used for secondary purposes, unrelated to their direct care (Lelliott, 2003). Again, it is uncertain for each person whether these concerns will be realized.

\section{Exploring Laypeople's Computer-Mediated Information Sharing Choices}

What we know about laypeople's views of electronic access to their personal health information comes from surveys where respondents were asked abstract questions about participation in health information exchange and PHR systems (Americans Support, 2005; Attitudes of Americans, 2005; Two in Five Adults, 2004). In their survey of 800 adults, the Markle Foundation described an exchange to participants as follows:

Now let's imagine that a nationwide health information exchange or network were set up for doctors and patients ... Only with the patient's permission could their medical information be shared through this network. The patient would control what information from their medical records is made available to other physicians... (Attitudes of Americans, 2005)

Survey respondents rated system security and privacy as their highest priorities (Americans Support, 2005; Attitudes of Americans, 2005). In another survey of 2,242 adults, Harris Interactive asked what serious concerns participants had regarding keeping an online personal or family health record. Participants mentioned privacy $(68 \%)$ and security $(66 \%)$ concerns most often (Two in Five Adults, 2004).

The results of these studies show that laypeople do have concerns about electronic access to their health information and that these concerns center on issues of privacy and security. Despite having information about laypeople's abstract attitudes regarding health information exchange, we do not know what choices laypeople are likely to make if given the option to grant access rights to their health information.

In this study, we evaluated whether the use of realistic decision scenarios provides additional insight into laypeople's choices about electronically sharing their medication information, as compared to laypeople's responses to abstract survey questions. By our term "realistic decision scenario," we mean presenting each participant with a realistic representation of a choice they are likely to make in the future. We also presented participants with realistic decision scenarios concerning other patients, and asked the participants to make recommendations to these patients. By using this form of knowledge elicitation, we were able to conduct interviews with participants while they completed a structured task (Crandall, Klein, \& Hoffman, 2006). In this study, we used current policy discussions and technical developments to construct a computer interface that participants used while making their choices about electronically sharing their medication information.

\section{METHOD}

\section{Study Participants}

This study consisted of interviews with participants $(\mathrm{N}=31)$ in a clinic setting. Eligible study participants were Englishspeaking adult patients who visited a neurology clinic in Madison, WI, USA, were at least 18 years old, and were taking at least one medication. Eligible patients also had full mental function as judged by their physician. Physicians weeded 
out patients with exceptionally poor mental function, such as those who suffer from mental deterioration due to the effects of late-stage diseases like Parkinson's disease. We relied on clinic physicians to make this judgment and did not verify their assessments with the patients' clinical charts. We did not impose any further inclusion or exclusion requirements for the study. Human Subjects approval for the study was obtained through the University of Wisconsin Madison Health Sciences IRB.

During recruitment, we were on-site at the clinic. As patients met with their clinic physician, they were given a small slip of paper briefly describing the opportunity available for them to participate in the study, their time commitment and incentive for participation. We put little additional information about the study on the sheet for the purpose of not discouraging participation by those who might naturally be non-sharers. If patients were interested in participating, they told their physician or nurse, who then notified the study interviewer.

We selected neurology patients as a study population because we thought they would be managing complex illnesses for which medication management would be an important part of their care. We expected study participants would be taking 1) a greater number of medications than the average population, and 2) medications that may reveal underlying diagnoses that are socially labeled.

\section{Study Procedure}

During the interview with each participant, the participant generated a list of his/her medications using an electronic form. (S)he then electronically chose to share (or not) information about each of his/her medications with three physician-types. These physician-types - the participants' primary care physician, his/her neurologist, and an emergency room physician-were chosen to represent a range of physicians, with key differences shown in Table 1.

\begin{tabular}{|c|c|c|c|}
\hline \multicolumn{2}{|c}{ Primary Care Physician } & Neurologist & Emergency Room Physician \\
\hline Focus of Care Provided & general health & specific problem & specific problem \\
\hline Knowledge Base of Provider & generalist & specialist & generalist \\
\hline Planning Horizon for Visit & scheduled & scheduled & urgent \\
\hline
\end{tabular}

Table 1. Key Differences in Physician-Types

The participant viewed a matrix with the names of his/her medications in the leftmost column. Across the top of the matrix were the names of the three physician-types, and a box was located at each intersection of medication and physician-type. By checking a box, the participant was choosing to share information about one medication with one physician-type. We collected data using Microsoft Access ${ }^{\circledR}$ database forms on a laptop computer, as laypeople are likely to make PHR sharing choices using a computer interface. Figure 1 shows what this matrix of sharing choices would have looked like for Kristine. While making his/her sharing choices, the participants described the reasons (s)he made the choices (s)he did.

\begin{tabular}{|c|ccc|}
\hline Keppra & $\begin{array}{c}\text { Primary Care } \\
\text { Physician }\end{array}$ & Neurologist & $\begin{array}{c}\text { Emergency } \\
\text { Room } \\
\text { Physician }\end{array}$ \\
\hline Lexapro & $\square$ & $\square$ & $\square$ \\
\hline Lipitor & $\square$ & $\square$ & $\square$ \\
\hline Multivitamin & $\square$ & $\square$ & $\square$ \\
\hline & $\square$ & $\square$ & $\square$ \\
\hline
\end{tabular}

Figure 1. Matrix of Sharing Choices for a Sample Participant

A research consultant trained as a Registered Nurse and Nurse-Practitioner rated the participant's medications according to the likelihood of clinical care benefits and information disclosure concerns resulting from sharing the participant's specific medication information. Each medication was rated according to two clinical care benefits: 1) the medication's potential for interactions with foods or other medications and 2) the need for follow-up care and/or monitoring on the medication. Each medication was also rated according to two information-disclosure concerns: 1) social labeling attached to the medication and 2) use of information about the medication other than for the patient's direct care. The research consultant rated each participant's medication on a scale of low, moderate and high. Her 
background as a nurse with prescribing capabilities gave her the qualification of being able to judge medications according to both clinical care benefits and information-disclosure concerns.

Additionally, we read and showed participants four vignettes about other people considering sharing their medication information. After hearing and seeing each vignette, the participant gave a recommendation to the person in the story. The participant also provided the reason(s) for his/her recommendation, including potential benefits and/or concerns (s)he saw present for the person in the vignette. The four vignettes were designed to each represent a different combination of potential clinical care benefits and information-disclosure concerns, shown in Table 2.

Vignette 1 (High Clinical Care Benefit, Low Information Disclosure Concern):

Camille is a 36-year-old single mother with two young children. She suffers from allergies, which cause her eyes to itch and water and her nose to run. She takes the medication Zyrtec to reduce her allergy symptoms. Camille has been feeling very sad over the past 2 months and doesn't know why. She decided to talk to her primary care physician about these sad feelings, and her physician referred her to a psychiatrist. Camille expects the psychiatrist will prescribe an anti-depressant for her. Should Camille extend the permissions in her electronic personal health record to share her prescription information for Zyrtec with her psychiatrist? Why do you give this recommendation?

Vignette 2 (Low Clinical Care Benefit, High Information Disclosure Concern):

Jorge went through gastric bypass surgery just over a year ago to lose weight. He is now 27-years-old, has lost over 100 pounds and has moved to a new city to" start over." Before his surgery, Jorge struggled with both diabetes and high blood pressure. He has remained on reduced dosages of an ACE inhibitor for blood pressure and a Thiazolidinedione for diabetes. Jorge suffers from acne and has been referred by his primary care physician to a dermatologist. The primary care physician has told Jorge that these medications are not causing his acne and will not interact with any medications the dermatologist might prescribe. Should Jorge extend the permissions in his electronic personal health record to share his diabetes and blood pressure medication information with his dermatologist? Why do you give this recommendation?

Vignette 3 (High Clinical Care Benefit, High Information Disclosure Concern):

Earnest is 54-years-old and is HIV-positive but hasn't told any of his friends or family members. He now takes a series of medications to stay healthy. Earnest has recently been having chest pains while he exercises, but he didn't give these pains much thought. Unfortunately, shortly after these pains started, Earnest had a heart attack while at work. Co-workers called an ambulance and one co-worker met the ambulance at the hospital to make sure Earnest was alright. Should Earnest extend the permissions in his electronic personal health record to share his medication information related to HIV with the emergency room physician? Why do you give this recommendation?

Vignette 4 (Low Clinical Care Benefit, Low Information Disclosure Concern):

Kristine is a healthy 62-year-old woman. She does not take any prescription medications but does take several common vitamin supplements. She recently went to her primary care physician for her annual physical. Should Kristine extend the permissions in her electronic personal health record to share information about the vitamins she takes with her primary care physician? Why do you give this recommendation?

\section{RESULTS}

We expected that study participants would be taking 1) a greater number of medications than the average population and 2) medications that may reveal underlying conditions that are socially labeled. Study participants reported taking, on average, 5.23 prescription medications each. The percent of the U.S. population taking 3 or more prescription medications in the past month is under 20\% (Health, United States, 2006). The percentage of study participants currently taking 3 or more prescription medications was just over $87 \%$. Many participants were taking medications for anxiety, depression, or other mental health concerns, in addition to medications for Multiple Sclerosis, Parkinson's disease or seizure disorders. Of the 225 non-unique medications reported by participants, $56(24.89 \%)$ were rated by the research consultant as having high potential for social labeling.

Where abstract surveys provided general assessments of laypeople's perceptions, our realistic decision scenarios required participants to commit to choices and explain the rationale for their choices. The results of the decision scenarios provide significant insight into both laypeople's sharing choices and the rationale for their choices.

\section{Laypeople's Sharing Choices}

Tables 2, 3 and 4 show the differences in data gleaned from the abstract survey results and the results of this study. Where Table 2 displays laypeople's general feelings about health information exchange and personal health record systems, Table 3 argues that laypeople may be quite willing to share their medication information through these systems. Table 4 again shows that participants generally recommended sharing medication information across a variety of vignettes - though they were least likely to recommend sharing information about vitamins. 


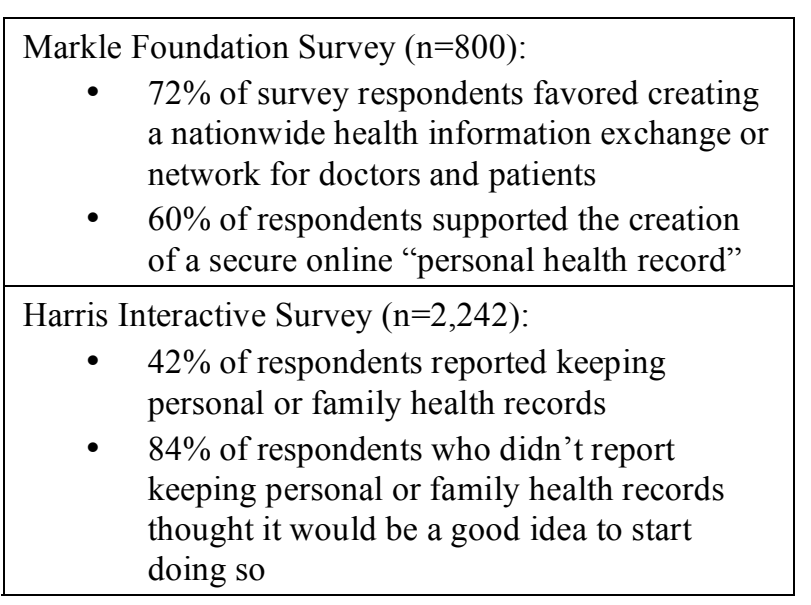

Table 2. Survey Results: Participation Choices

\begin{tabular}{|c|c|}
\hline & $\begin{array}{c}\text { Number of } \\
\text { Participants }\end{array}$ \\
\hline $\begin{array}{c}\text { Shared No Medication } \\
\text { Information }\end{array}$ & 0 \\
\hline $\begin{array}{c}\text { Shared Some Medication } \\
\text { Information }\end{array}$ & 1 \\
\hline $\begin{array}{c}\text { Shared All Medication } \\
\text { Information }\end{array}$ & 30 \\
\hline
\end{tabular}

Table 3. Decision Scenario: Sharing Choices

\begin{tabular}{|c|c|}
\hline $\begin{array}{c}\text { Recommended Sharing in } \\
\text { Vignette 1 (Allergies) }\end{array}$ & Number of Participants \\
\hline $\begin{array}{c}\text { Recommended Sharing in } \\
\text { Vignette 2 (Weight Loss) }\end{array}$ & 31 \\
\hline $\begin{array}{c}\text { Recommended Sharing in } \\
\text { Vignette 3 (HIV) }\end{array}$ & 31 \\
\hline $\begin{array}{c}\text { Recommended Sharing in } \\
\text { Vignette 4 (Vitamins) }\end{array}$ & 27 \\
\hline
\end{tabular}

Table 4. Vignettes: Sharing Recommendations

The study participants did not always choose to share other types of personal information. Two participants chose not to share their household annual income with the interviewer but then chose to share all of their medication information with the physicians discussed.

\section{Laypeople's Rationale for their Sharing Choices}

Tables 5, 6 and 7 show the differences in laypeople's privacy- and security-related concerns between the data gleaned from surveys and our study results. In this study, participants' statements of rationale were noted based on whether their statement of rationale addressed one or more of several categories. Table 6 lists the number and percent of participants who mentioned privacy, security or confidentiality in the statement of rationale for the own sharing choices. Table 7 lists the number and percent of participants who mentioned privacy, security or confidentiality in the statement of rationale for at least one of the individuals in the vignettes.

In abstract surveys, laypeople also often mentioned concerns related to privacy and security of their information. In this study, only seven participants mentioned privacy, security or confidentiality of their medication information in their rationale statements. Yet, all seven of those participants still chose to share all of their medication information with all three types of physicians. Only six participants acknowledged these issues when they stated why they gave a particular recommendation to one of the individuals in the vignettes.

Using a realistic decision scenario to guide participant interviews provided new and valuable information about the decision criteria most important to laypeople. In this case, participants may have had concerns about sharing their medication information but the potential benefits of sharing outweighed their concerns. While participants did have abstract concerns related to PHRs, their responses demonstrate that their concerns related to privacy and secondary use of their information were not the key factors contributing to their sharing choices. 


\begin{tabular}{|c|}
\hline $\begin{array}{l}\text { Markle Foundation Survey }(\mathrm{n}=800): \\
\text { - }\end{array}$ \\
$\begin{array}{l}\text { Survey respondents rated } \\
\text { system security and privacy as } \\
\text { their highest priorities }\end{array}$ \\
\hline $\begin{array}{l}\text { Harris Interactive Survey }(\mathrm{n}=2,242): \\
\text { The concerns mentioned by } \\
\text { participants most often were } \\
\text { privacy }(68 \%) \text { and security } \\
(66 \%)\end{array}$ \\
\hline
\end{tabular}

Table 5. Survey Results: Privacy and Security Concerns

\begin{tabular}{|l|c|c|}
\hline & $\begin{array}{c}\text { Number of } \\
\text { Participants } \\
\text { Mentioning }\end{array}$ & $\begin{array}{c}\text { Percent of } \\
\text { Participants } \\
\text { Mentioning }\end{array}$ \\
\hline $\begin{array}{l}\text { Maintaining Privacy, Security or } \\
\text { Confidentiality of the Information }\end{array}$ & 7 & $22.58 \%$ \\
\hline
\end{tabular}

Table 6. Decision Scenario: Rationale Statements

\begin{tabular}{|l|c|c|}
\hline & $\begin{array}{c}\text { Number of } \\
\text { Participants } \\
\text { Mentioning }\end{array}$ & $\begin{array}{c}\text { Percent of } \\
\text { Participants } \\
\text { Mentioning }\end{array}$ \\
\hline $\begin{array}{l}\text { Maintaining Privacy, Security or } \\
\text { Confidentiality of the Information }\end{array}$ & 6 & $19.35 \%$ \\
\hline
\end{tabular}

Table 7. Vignettes: Rationale Statements

\section{DISCUSSION}

Contemporary policies regarding health information technology development, including personal health records (PHRs), promote laypeople making discrete choices about whether to share specific personal health information with a range of providers. These assumptions are driven partially by surveys that outline the privacy- and security-related concerns laypeople have regarding sharing their health information electronically.

It is clear from this study that we need to understand the actual choices decision-makers will make under various policy frameworks. Policies regarding PHR access rights must account for the cognitive demands placed on laypeople as a result of the policies. In this study, addressing only medications and only three types of physicians, some study participants had to make thirty discrete sharing choices.

The study results also suggest that using realistic decision scenarios will provide additional value over the abstract opinion surveys traditionally used to guide policymaking. By asking participants to make choices instead of respond to abstract questions, the participants have to commit more concretely to a course of action and must think more practically about the relative importance of their decision criteria.

\section{ACKNOWLEDGMENTS}

We thank the members of the Health Systems Lab for their support. We also thank Amy Brady and the conference reviewers for their thoughtful suggestions.

\section{REFERENCES}

Americans Support Online Personal Health Records; Patient Privacy and Control over their own Information are Crucial to Acceptance. (2005). Washington, DC: Markle Foundation.

Aspden, P., Wolcott, J., Bootman, J. L., \& Cronenwett, L. R. (2006). Preventing Medication Errors: Quality Chasm Series. Washington, DC: The National Academies Press.

Attitudes of Americans Regarding Personal Health Records and Nationwide Electronic Health Information Exchange. (2005). Washington, DC: Markle Foundation.

The Children's Hospital Informatics Program (CHIP). (2007). Retrieved September 16, 2008, from http://www.chip.org/

Consumer Empowerment: Consumer Access to Clinical Information. (2007). Washington, DC: Office of the National Coordinator for Health Information Technology (ONC).

Crandall, B., Klein, G. A., \& Hoffman, R. R. (2006). Working Minds: A Practitioner's Guide to Cognitive Task Analysis. Cambridge, Mass.: MIT Press.

Hadjikoutis, S., Morgan, J. E., Wild, J. M., \& Smith, P. E. (2005). Ocular Complications of Neurological Therapy. European Journal of Neurology, 12(7), 499. 
Health, United States. (2006). Hyattsville, MD: Department of Health and Human Services Centers for Disease Control and Prevention and National Center for Health Statistics.

Holmes-Rovner, M., \& Wills, C. E. (2002). Improving informed consent: insights from behavioral decision research. Medical Care, 40(9 Suppl), 30.

Kaplan, B. (2001). Evaluating informatics applications--clinical decision support systems literature review. International Journal of Medical Informatics, 64(1), 15-37.

Lelliott, P. (2003). Secondary Uses of Patient Information. Advances in Psychiatric Treatment, 9(3), 221.

Michels, R. D., \& Meisel, S. B. (2003). Program Using Pharmacy Technicians to Obtain Medication Histories. American Journal of Health-System Pharmacy, 60(19), 1982.

Opportunities for CMS Actions in Support of Personal Health Records. (2005). New York: Connecting for Health Steering Group and the Personal Health Technology Council.

Rintamaki, L. S., Davis, T. C., Skripkauskas, S., Bennett, C. L., \& Wolf, M. S. (2006). Social Stigma Concerns and HIV Medication Adherence. AIDS Patient Care \& STDs, 20(5), 359.

Say, R. E., \& Thomson, R. (2003). The Importance of Patient Preferences in Treatment Decisions-Challenges for Doctors. British Medical Journal, 327(7414), 542-545.

Sengupta, S., Pungrassami, P., Balthip, Q., Strauss, R., Kasetjaroen, Y., Chongsuvivatwong, V., et al. (2006). Social Impact of Tuberculosis in Southern Thailand: Views from Patients, Care Providers and the Community. The International Journal of Tuberculosis and Lung Disease, 10(9), 1008.

Sher, I., McGinn, L., Sirey, J. A., \& Meyers, B. (2005). Effects of Caregivers' Perceived Stigma and Causal Beliefs on Patients' Adherence to Antidepressant Treatment. Psychiatric Services, 56(5), 564.

Tang, P. C., Ash, J. S., Bates, D. W., Overhage, J. M., \& Sands, D. Z. (2006). Personal Health Records: Definitions, Benefits, and Strategies for Overcoming Barriers to Adoption. Journal of the American Medical Informatics Association, 13(2), 121.

Two in Five Adults Keep Personal or Family Health Records and Almost Everybody Thinks This Is a Good Idea. (2004). Rochester, NY: Harris Interactive.

The Value of Personal Health Records: A Joint Position Statement for Consumers of Health Care. (2007). Journal of AHIMA, 78(4).

Yasnoff, W. A., Humphreys, B. L., Overhage, J. M., Detmer, D. E., Brennan, P. F., Morris, R. W., et al. (2004). A Consensus Action Agenda for Achieving the National Health Information Infrastructure. Journal of the American Medical Informatics Association, 11(4), 332. 